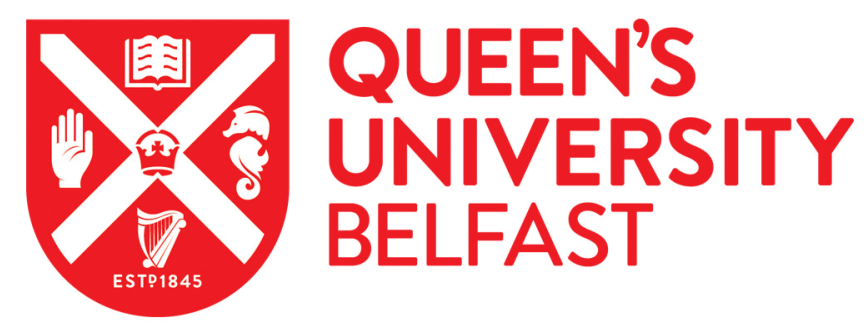

\title{
Paramphistomosis of Ruminants: An Emerging Parasitic Disease in Europe
}

Huson, K. M., Oliver, N. A. M., \& Robinson, M. W. (2017). Paramphistomosis of Ruminants: An Emerging

Parasitic Disease in Europe. Trends in Parasitology, 33(11), 836-844. https://doi.org/10.1016/j.pt.2017.07.002

Published in:

Trends in Parasitology

Document Version:

Peer reviewed version

Queen's University Belfast - Research Portal:

Link to publication record in Queen's University Belfast Research Portal

Publisher rights

Copyright 2017 Elsevier Ltd.

This work is made available online in accordance with the publisher's policies. Please refer to any applicable terms of use of the publisher.

\section{General rights}

Copyright for the publications made accessible via the Queen's University Belfast Research Portal is retained by the author(s) and / or other copyright owners and it is a condition of accessing these publications that users recognise and abide by the legal requirements associated with these rights.

Take down policy

The Research Portal is Queen's institutional repository that provides access to Queen's research output. Every effort has been made to ensure that content in the Research Portal does not infringe any person's rights, or applicable UK laws. If you discover content in the Research Portal that you believe breaches copyright or violates any law, please contact openaccess@qub.ac.uk. 


\section{Paramphistomosis of ruminants: An emerging parasitic disease in Europe}

Kathryn M. Huson, Nicola A.M. Oliver and Mark W. Robinson*

Institute for Global Food Security, School of Biological Sciences, Queen's University Belfast, 97 Lisburn Road, Belfast, Northern Ireland.

*Correspondence: mark.robinson@ qub.ac.uk (M.W. Robinson).

Keywords: Paramphistome, rumen fluke, Calicophoron daubneyi, proteomics, transcriptomics, anthelmintic, diagnostic. 


\section{Abstract}

2 Whilst historically regarded as being of minor importance in European livestock, recent

3 evidence suggests that the prevalence of paramphistomosis is greater than that of fasciolosis

4 in parts of the UK. In order to address this emerging threat to ruminant farming systems, and 5 associated risks for food security posed by rumen fluke infection, it is imperative that we 6 develop a better understanding of the basic biology of this parasite and how it interacts with

7 its ruminant host. In this opinion article we will review recent progress in tracking the spread 8 of rumen fluke infection in Europe, and propose some research questions that should be 9 addressed if we are to develop tools to diagnose and treat paramphistomosis more effectively in the future.

\section{The paramphistomes}

Paramphistomes (see Glossary), commonly known as rumen or stomach flukes, are digenean parasites that infect ruminant animals across a wide geographical range of countries as far apart as Mexico, India, Finland and Australia [1-4]. Paramphistome parasites belong to several different genera within the family Paramphistomidae, and all require an intermediate snail host and a definitive ruminant host within their lifecycle. Within the intermediate host the paramphistomes develop through three larval stages (sporocysts, rediae and cercariae) and undergo asexual reproduction before cercariae emerge from the snail and encyst as metacercariae. Infection of the definitive host occurs upon ingestion of vegetation harbouring dormant encysted metacercariae. The metacercariae then excyst in the small intestine (duodenum) before migrating through the upper gastro-intestinal tract (GIT) to the rumenreticulum, where the mature parasites reside. Figure 1 illustrates this lifecycle for the species 
Mature paramphistomes are pink pear-shaped organisms, typically $0.5-1.0 \mathrm{~cm}$ long,

that are firmly attached to the host rumen wall by a posterior muscular acetabulum (Figure 2).

They have a blind-ended, bifurcated gut with an oral opening protruding into the rumen at their narrower anterior end [5]. Immature stages of the parasite are much smaller at less than a millimetre in length and appear within the small intestine, as early as 9 days after exposure to infected pasture, as small nodules/dark spots, in association with haemorrhagic lesions of the superficial mucosal tissue [6,7]. Small rumen flukes, which are bright red in colour and around 2-3 $\mathrm{mm}$ in length but with similar external morphology to mature specimens, have been described within the rumen from day 38 post-exposure to infected pasture [6] as they complete their migration from the duodenum.

It is the newly excysted and migratory stages of the parasite that are thought to be responsible for clinical paramphistomosis; a condition regarded as a leading cause of livestock morbidity which results in economic loss in tropical and sub-tropical regions $[1,4,8]$. Clinical symptoms include lethargy/recumbency, dehydration, severe scour and submandibular oedema, which occur as immature parasites excyst and penetrate the duodenal mucosa causing significant damage to the tissues [9]. In cases with large burdens of immature rumen fluke, mortality may occur as a result of the damage caused to host intestinal tissue and symptoms of haemorrhagic enteritis including anaemia and hypoproteinaemia $[7,10]$. Mature paramphistome infections have been associated with ruminal papillae atrophy and ulceration, at the point of fluke attachment $[11,12]$, and negative impacts on production measures such as milk yields and growth rates have also been reported [13,14].

In this article we will highlight the growing prevalence of paramphistome infections in Western Europe, and the sparsity of data on the basic biology of these parasites. Key areas for future research will be proposed that support the development of diagnostic tools and 
treatment options to enable the sustainable control of this emerging parasitic infection in the future.

\section{Paramphistomosis is an emerging infection in European livestock}

Historically, rumen fluke infection was rarely seen in the temperate climates of Western Europe. However, morphological identifications in the 1950s suggested that Paramphistomum cervi (or species later considered synonymous with $P$. cervi) was resident in Great Britain and Ireland [15] and Italy [16]. Since then, rumen fluke have persisted as a little acknowledged infection that many livestock producers remain unaware of. However, in recent years, significant increases in the prevalence of rumen fluke infections have been noted in ruminant livestock populations across western European countries. Using molecular sequence data, the species Calicophoron daubneyi has been clearly identified as the primary rumen fluke parasite infecting cattle, sheep and goats in Europe [17-20]. Prevalence levelsas high as $29-36 \%$ in Spain [21,22], 20\% in France [23], and 59\% in Wales [24] in cattle, and up to $77 \%$ in Ireland [18] and $42 \%$ in Wales [24] in sheep have now been reported (Table 1). The factors driving these increased levels are not fully understood, but the introduction of $C$. daubneyi to Western Europe during the movement of livestock [5], the presence of a suitable snail intermediate host $[25,26]$, and climate change (milder winters and higher rainfall) favouring the completion of the parasite lifecycle [27] are all thought to contribute.

Although clinical disease and mortality owing to rumen fluke infections remain infrequent in temperate regions, fatal disease outbreaks, linked to significant immature parasite burdens, have been reported in both sheep and cattle $[7,10]$. Additional anecdotal reports from veterinarians and farmers indicate that paramphistomosis may be a rising problem in some areas. With a growing geographical range, and a demonstrable potential to 
cause significant clinical disease, interest and concern is growing among both veterinarians and livestock producers regarding the potential impact of this parasite on animal health, productivity and welfare, and how this threat should be tackled.

\section{Highly prevalent but poorly understood: how much do we know?}

Despite their ubiquitous presence, our current knowledge of the fundamental molecular and developmental biology of rumen fluke is limited, particularly in comparison to other trematodes of veterinary significance such as the liver fluke, Fasciola hepatica. For instance, histochemical staining, as well as morphological and ultrastructural studies, have detailed the anatomy of several paramphistome species $[3,5,28,29]$, but such work has largely focused on larval stages within the intermediate host or adult rumen-dwelling flukes that are easier to collect, mostly belonging to tropical and sub-tropical species of paramphistome to date. To our knowledge, the development of various organ systems (e.g. the tegument, gut, and reproductive structures) in the newly excysted and migratory stages has not yet been described for $C$. daubneyi, and only a few studies have been carried out which describe the development of other paramphistomes [30]. Uncertainty also exists regarding the feeding mechanisms used by the various life-cycle stages within the ruminant host. Based on a transcriptome analysis, Choudary et al. [31] proposed that mature $P$. cervi rumen flukes may obtain nutrition via damaged capillaries in the rumen wall allowing uptake of glucose and other nutrients directly from the bloodstream. However, the orientation of the parasite within the host - anchored by a blind-ended muscular acetabulum with their oral opening (which leads to the parasite gut) protruding away from the rumen wall - would indicate that the rumen contents are the primary source of nutrition for the parasite. Indeed, research dating back to the 1950s [32] has shown that rumen fluke can be sustained for a prolonged period 
outside the host, with a supply of rumen fluid. Microscopic examination of mature rumen fluke showed rumen material, including Protozoa, within the parasite oesophagus, also suggesting that paramphistomes may feed on components of the rumen fluid digesta or microbiome [3]. Absorption of nutrients directly across the tegument is thought to be unlikely given its thickness in paramphistomes and a lack of mitochondria in the outer tegumental syncytium required for active transport mechanisms [28]. In contrast, ingested host tissue has been observed within the gut of an immature rumen fluke collected from the small intestine of a calf at post mortem [10]. The proposed switch from feeding on host tissue, in the small intestine, to digesta (or microbial contents) in the rumen as these parasites develop poses interesting questions about how they interact with their host during their migration along the GIT.

Perhaps due to their lack of recognition and poorly understood pathogenicity, no anthelmintic drugs (asides from a single formulation of oxyclozanide licensed only in France: Douvistome) are currently available with a label claim for rumen fluke control in Western Europe. Numerous studies, both in vitro and in vivo, have attempted to verify the efficacy of existing anthelmintics against a range of rumen fluke species [33-35]. Currently, oxyclozanide (normally marketed as a treatment for liver fluke) is the drug of choice to control both immature and mature paramphistome infections, although this drug does not appear to have been tested against immature C. daubneyi specifically [36]. Additionally, research into diagnostic tools for paramphistomosis has been very limited [37,38], and currently no diagnostic test has been developed for the identification of pre-patent infections, leaving faecal egg counts (FEC) or post mortem as the only options to identify chronic or acute disease respectively. Research on other trematodes has benefited from significant transcriptome and genome [39] datasets that facilitate comparative studies between life-cycle stages and species, as well as proteomics investigations to identify putative drug or vaccine 
targets [40-42]. For the paramphistomes, only a single transcriptome assembly for adult $P$. cervi has been published, but the assembled contigs have not been made publically available [31]. Similarly, proteomic data for paramphistomes are sparse. Due to the lack of transcriptome/genome datasets most studies so far have simply described the proteome profile of excretory/secretory or somatic proteins (visualised by SDS-PAGE) and identified antigenic components by Western blot using sera from paramphistome infected animals [38,43-45]. These studies have focussed on tropical paramphistome species and, to date, there are no published studies on the proteome of $C$. daubneyi found in Europe.

\section{New developments and discoveries}

The renewed interest in paramphistomes in temperate climates has sparked several new studies and publications in the last few years. Since Gordon et al. [20] proposed C. daubneyi as the primary rumen fluke species infecting livestock in Britain in 2013, a number of studies have been conducted in the UK and Ireland, all of which have confirmed this finding using molecular approaches to species identification [46-48]. Studies across Western Europe, in the Netherlands [49], Belgium [50], Italy [51] and Spain [17] have also confirmed, using molecular tools, the predominant rumen fluke species identified in livestock to be $C$. daubneyi. A study in Ireland [18] confirmed a high prevalence of C. daubneyi in Irish sheep flocks, but also identified infection with another rumen fluke species, Paramphistomum leydeni, in a single animal. One case of $P$. leydeni infection in cattle has also been reported in the Netherlands [49]. This suggests that occasional infection from ruminant wildlife reservoir hosts, where P. leydeni has been identified previously [52], may also occur in livestock.

Looking for possible interaction between endemic F. hepatica and C. daubneyi on Welsh farms, Jones et al. [24] reported a significant negative correlation between infection 
146 levels based on FECs for each parasite; lower egg counts were seen for C. daubneyi in 147 animals with a high FEC result for $F$. hepatica, and vice versa. Furthermore, it has now been confirmed that $C$. daubneyi and $F$. hepatica share the same key host snail; Galba truncatula [26]. Studies of the interactions between these two species at the intermediate host level will be important to inform our understanding of the dynamics of trematode infection and possible co-infection within $G$. truncatula populations, and to better understand the ecology and epidemiology that underpin the risk factors for livestock infections [24]. It appears that successful co-infections (where cercariae and infective metacercarial cysts are produced) between these two species within an individual intermediate host are normally not seen under field conditions, even when both $C$. daubneyi and $F$. hepatica are present in the same snail population [53,54]. Successful co-infections producing metacercariae have been demonstrated in the laboratory $[55,56]$, and reported from a small number of naturally infected lymnaeid snails in France [56]. However, co-infection prevalence in the snail population included in this study was $<1 \%$, further indicating the rarity of such co-infections. chronic paramphistome infection. Histological examination demonstrated localised tissue damage and infiltration of inflammatory cell populations (mainly CD3+ T cells) at the site of attachment of mature rumen fluke to the ruminal papillae [12,57]. Cytokine analysis suggested a localised Th1 immune response with upregulation of IFN $\gamma$ and IL-10 in response to paramphistome infection in the rumen [57]. This evidence of an active immune response 
during chronic paramphistomosis is interesting in light of the supposed 'well-tolerated' status of mature rumen fluke by the host [48]. Whilst this tolerance is widely referred to, it is unclear what this really means for the host and any mechanism actively used by rumen fluke to promote this has not been characterised. Whilst the limited penetration by the adult parasites into host tissue will contribute to this, it is also likely that rumen flukes, like other helminth parasites, secrete immunomodulators to promote their survival in the mammalian host [58-61]. Alternatively, given the rich diversity of commensal gut microbes within the rumen fluid, these parasites may benefit from microbiome-induced immune modulation [62] but further research is required to investigate any such interactions. There is some evidence paramphistome infections $[4,6]$, but it is not yet clear how long-lasting any effect may be, and if this is sufficient to prevent clinical disease upon repeat infections in the same or future grazing seasons.

Whilst production effects caused by tropical paramphistome species have been reported [1,13], it is not yet clear if sub-clinical disease, specifically due to chronic $C$. daubneyi infection, has a significant impact on animal productivity or welfare in temperate areas. Although limited by a small sample size $(\mathrm{n}=6)$, an abattoir study by Bellet et al. [47] did suggest a negative correlation between rumen fluke infection and cold carcass weights and fat coverage at slaughter in British cattle. Malrait et al. [50] also identified an association between rumen fluke infection and poor faecal consistency scores in Belgian cattle.

Based on FEC reduction tests in cattle, oxyclozanide was shown to be the most effective existing flukicide (compared with albendazole, netobimin and closantel) against $C$. daubneyi infection [35]. Closantel displayed a slightly lower efficacy against mature $C$. daubneyi but in other studies this drug was ineffective against paramphistomes $[33,50]$. To date, the efficacy of different anthelmintics against immature $C$. daubneyi, which are 
responsible for most pathology in infected animals, has yet to be investigated. Conducting drug efficacy tests in vivo against immature paramphistomes is challenging, owing to the current lack of a diagnostic test for pre-patent infections or a suitable animal model for experimental infection. Some efforts towards diagnostic development have been made recently: Anuracpreeda et al. developed a diagnostic sandwich ELISA, based on detection of a $16 \mathrm{kDa}$ protein from a Paramphistomum gracile whole worm extract $[37,63,64]$. This offers hope for the development of antibody-based diagnostic tools (e.g. for serum, bulk milk and saliva) for $C$. daubneyi in the future. Perhaps most desirable would be the development of a coproantigen test similar to that available for $F$. hepatica [65]. These tests are not invasive, and are able to identify current infections by direct detection of parasite antigens. This is a major advantage over traditional serology based diagnostics which detect specific host antibodies and therefore cannot discriminate between active infections and previous host exposure [65].

\section{Research priorities: Playing catch-up}

Rumen fluke have been much neglected in recent parasitological research efforts. However, there is now a pressing need to re-examine these parasites in order to understand how they interact with, and impact on, their ruminant hosts in the temperate climates and intensive farming practices of Western Europe (see Outstanding Questions). The success of much of this basic research ultimately hinges on the generation of large scale "omics" datasets for paramphistomes in general, but particularly for $C$. daubneyi. Transcriptomic and proteomic studies of $C$. daubneyi should reveal host-exposed molecules that are secreted by the parasite or presented on the tegumental surface. As seen with other trematodes $[40,42]$, many of these molecules are likely to be antigenic and represent important diagnostic or vaccine candidates. 
220 It is now recognised that many helminths also export a variety of protein and RNA 221 molecules, including potential diagnostic/vaccine targets, packaged within extracellular vesicles [58,66-69]. Their characterisation in $C$. daubneyi may provide a further source of diagnostic antigens whilst revealing mechanisms of interaction between rumen flukes and their ruminant hosts.

Further in-depth studies of these parasites within their intermediate snail host are also needed.

These efforts may reveal opportunities to introduce parasite control measures to prevent transmission via the intermediate host [54], and inform understanding of epidemiological factors impacting lifecycle stages outside the definitive host. Knowledge of the dynamics of trematode infections within their intermediate hosts may further aid the identification of risk factors for both $F$. hepatica and $C$. daubneyi infections [24,53] and allow risk prediction models to be developed.

Because clinical paramphistomosis is invariably associated with burdens of immature parasites in the small intestine [7,10], it is imperative to study these juvenile and migratory life-cycle stages as well as the adult flukes that are more easily recovered from the rumen. Comparative proteomics studies may reveal how the antigenic profile of the parasite changes as it matures, and identify virulence factors involved in pathogenicity. Similar approaches, in other helminth species, have identified key molecules involved in parasite feeding/infectivity (such as the cathepsin L family of $F$. hepatica [70]) that are now being validated as targets for parasite control using RNA interference [71,72]. Understanding how $C$. daubneyi establishes infection within the small intestine, and how it feeds as it migrates along the GIT, may also present similar opportunities for rumen fluke control. 
daubneyi secreted antigens are developmentally expressed, it may be possible to develop a diagnostic method capable of discriminating between acute and chronic stage infections $[73,74]$. Studying how the host immune system responds to infection will shed light on any immunomodulatory mechanisms employed by $C$. daubneyi and how these may impact on the ability of the host to respond to concurrent bacterial infections or mount an effective immune response against vaccine antigens. Thus, establishing suitable animal models of infection to study C. daubneyi immunology is a priority.

Given the foreseeable length of time and research effort required to develop a vaccine against $C$. daubneyi infections, the identification of effective anthelmintic treatments is critical. The current lack of a widely-licenced drug product for paramphistomosis, and the reliance on a single compound, oxyclozanide (often used off-licence), is far from desirable. With widespread drug resistance now affecting the control of a large range of parasitic and infectious diseases [75,76], reliance on a single drug compound raises the risk of untreatable isolates emerging, and is never good policy for sustainable parasite control. Future research may focus on the identification of novel compounds with efficacy against both juvenile and mature rumen fluke (or repositioning of existing drugs) and the selection and validation of new drug targets, using in vitro assays to assess anthelmintic efficacy against measurements such as fluke motility [77] or egg viability [78].

With paramphistomosis an established threat to sustainable agriculture in the tropics and sub-tropics [1,79], questions surrounding the exact sub-clinical, production or animal welfare impacts of chronic paramphistome infections in temperate climates are yet to be satisfactorily addressed. Comprehensive studies are now needed to establish the impact and importance of $C$. daubneyi infections within the ruminant livestock systems of Western

267 Europe, in order to inform veterinarians and livestock producers of appropriate control 
measures which may be necessary, or to alleviate concerns surrounding the emergence of this relatively unknown infection.

\section{Concluding remarks}

Based on recent survey work (Table 1), rumen fluke should now be considered an emerging parasitic infection of ruminant livestock in Europe. There are a number of significant challenges for the agricultural industries in the coming decades, including maintaining sustainable farming practices in the face of climate change and the need to feed an evergrowing world population. It will be essential to understand and manage all factors which may impact on livestock productivity and farming efficiency in order to overcome these hurdles. With paramphistomosis an emerging factor in European ruminant production systems, there is a clear need to quantify both production losses and the clinical threat from rumen fluke infection as well as to develop new diagnostic tools and therapeutic options. To gain a comprehensive understanding of this parasitic infection, large scale production trials, along with the development of 'omics' datasets, are urgently needed. Given the expansive data already available for other helminths, which pose a threat to livestock, a substantial effort is now required to bring our knowledge of paramphistome infections up to par.

\section{Acknowledgments}

This work was supported by a grant to M.W.R. (BB/N017757/1) from the BBSRC. N.A. M.O. is supported by a postgraduate studentship from the Northern Ireland Department for Employment and Learning (DEL). 


\section{References}

2931 Rangel-Ruiz, L.J. et al. (2003) Seasonal trends of Paramphistomum cervi in Tabasco, 294 Mexico. Vet. Parasitol. 116, 217-222

2952 Pavan Kumar, C. et al. (2016) Outbreak of immature paramphistomosis in Nellore $296 \quad$ Jodipi sheep. J. Parasit. Dis. 40, 533-535

2973 Nikander, S. and Saari, S. (2007) Notable seasonal variation observed in the morphology of the reindeer rumen fluke (Paramphistomum leydeni) in Finland. Rangifer 27, 47-57

4 Rolfe, P.F. et al. (1991) Epidemiology of paramphistomosis in cattle. Int. J. Parasitol. 21, 813-819

Eduardo, S.L. (1982) The taxonomy of the family Paramphistomidae Fischoeder, 1901 with special reference to the morphology of species occurring in ruminants. II. Revision of the genus Paramphistomum Fischoeder, 1901. Syst. Parasitol. 4, 189-238

Devos, J. et al. (2013) Paramphistomosis in sheep; natural infection of lambs by Calicophoron daubneyi. Rev. Med. Vet. (Toulouse). 164, 528-535

Mason, C. et al. (2012) Disease associated with immature paramphistome infection in sheep. Vet. Rec. 170, 343-344

Godara, R. et al. (2014) Epidemiology of paramphistomosis in sheep and goats in Jammu, India. J. Parasit. Dis. 38, 423-8

9 Tilling, O. (2013) Rumen fluke in cattle in the UK: a review. Livestock 18, 223-227

10 Millar, M. et al. (2012) Disease associated with immature paramphistome infection. Vet. Rec. 171, 509-510

11 Rolfe, P.F. et al. (1994) Pathology of infection with Paramphistomum ichikawai in sheep. Int. J. Parasitol. 24, 995-1004

12 Fuertes, M. et al. (2015) Pathological changes in cattle naturally infected by Calicophoron daubneyi adult flukes. Vet. Parasitol. 209, 188-196

13 Rojo-Vázquez, F.A. et al. (2012) Update on trematode infections in sheep. Vet. Parasitol. 189, 15-38

14 Foster, A.P. et al. (2008) Rumen fluke (paramphistomosis) in British cattle. Vet. Rec. $162,528-528$

5 Willmott, S. (1950) On the species of Paramphistomum Fischoeder, 1901 Occurring in Britain and Ireland with Notes on Some Material from the Netherlands and France. $J$. Helminthol. 24, 155-170

16 Deiana, S. and Arru, E. (1963) Further Inquiries on Paramphistomosis (Paramphistomum cervi) in Sardinia. Ric. Sci. 2. Ser. Pt. 2. Rend. B. 35, 449

17 Ferreras, M.C. et al. (2014) Calicophoron daubneyi (Paramphistomidae) in slaughtered cattle in Castilla y León (Spain). Vet. Parasitol. 199, 268-271 
18 Martinez-Ibeas, A.M. et al. (2016) Rumen fluke in Irish sheep: prevalence, risk factors and molecular identification of two paramphistome species. BMC Vet. Res. 12, 1-11

19 Arias, M. et al. (2011) Prevalence of mixed trematode infections in an abattoir receiving cattle from northern Portugal and north-west Spain. Vet. Rec. 168, 408

20 Gordon, D.K. et al. (2013) Identification of the rumen fluke, Calicophoron daubneyi, in GB livestock: Possible implications for liver fluke diagnosis. Vet. Parasitol. 195, $65-71$

21 González-Warleta, M. et al. (2013) Bovine paramphistomosis in Galicia (Spain): Prevalence, intensity, aetiology and geospatial distribution of the infection. Vet. Parasitol. 191, 252-263

22 Díaz, P. et al. (2007) Risk periods of infection by Calicophoron daubneyi (Digenea: Paramphistomidae) in cattle from oceanic climate areas. Parasitol. Res. 101, 339-342

23 Szmidt-Adjidé, V. et al. (2000) Prevalence of Paramphistomum daubneyi infection in cattle in central France. Vet. Parasitol. 87, 133-138

24 Jones, R.A. et al. (2016) Rumen fluke (Calicophoron daubneyi) on Welsh farms: prevalence, risk factors and observations on co-infection with Fasciola hepatica. Parasitology DOI: 10.1017/S0031182016001797

25 Abrous, M. et al. (1999) Infection of Lymnaea truncatula and Lymnaea glabra by Fasciola hepatica and Paramphistomum daubneyi in farms of central France. Vet. Res. 30, 113-118

26 Jones, R.A. et al. (2015) Confirmation of Galba truncatula as an intermediate host snail for Calicophoron daubneyi in Great Britain, with evidence of alternative snail species hosting Fasciola hepatica. Parasit. Vectors 8, 656

27 Skuce, P.J. et al. (2013) Animal health aspects of adaptation to climate change: beating the heat and parasites in a warming Europe. Animal 7, 333-345

28 Sharma, P.N. and Hanna, R.E. (1988) Ultrastructure and cytochemistry of the tegument of Orthocoelium scoliocoelium and Paramphistomum cervi (Trematoda: Digenea). J Helminthol 62, 331-343

29 Dinnik, J. a and Dinnik, N.N. (1957) Development of Paramphistomum sukari Dinnik, 1954 (Trematoda: Paramphistomidae) in a snail host. Parasitology 47, 209-16

30 Gupta, B.C. et al. (1987) Morphological and histochemical observations on the vitelline cells of developing and adult Paramphistomum cervi ( Trematoda : Digenea ). 31 Choudhary, V. et al. (2015) Transcriptome analysis of the adult rumen fluke
Paramphistomum cervi following next generation sequencing. Gene 570, 64-70

32 Willmott, S.M. and Pester, F.R.N. (1951) On the Transference of Adult Paramphistomum hiberniae Willmott , 1950 from One Definitive Host to Another of the Same Species . J. Helminthol. XXV, 93-96

33 Rolfe, P.F. and Boray, J.C. (1987) Chemotherapy of paramphistomosis in cattle. Aust. Vet. J. 64, 328-332

34 Paraud, C. et al. (2009) Efficacy of oxyclozanide against the rumen fluke Calicophoron daubneyi in experimentally infected goats. Vet. J. 180, 265-267 
Arias, M.S.S. et al. (2013) The efficacy of four anthelmintics against Calicophoron daubneyi in naturally infected dairy cattle. Vet. Parasitol. 197, 126-129

36 Selemetas, N. et al. (2015) The effects of farm management practices on liver fluke prevalence and the current internal parasite control measures employed on Irish dairy farms. Vet. Parasitol. 207, 228-240

37 Anuracpreeda, P. et al. (2017) Immunodiagnosis of paramphistomosis using monoclonal antibody-based sandwich ELISA for detection of Paramphistomum gracile circulating 16 kDa antigen. Parasitology DOI: 10.1017/S003118201600264X

Anuracpreeda, P. et al. (2013) Antigenic components, isolation and partial characterization of excretion-secretion fraction of Paramphistomum cervi. Exp. Parasitol. 133, 327-333

39 Cwiklinski, K. et al. (2015) The Fasciola hepatica genome: gene duplication and polymorphism reveals adaptation to the host environment and the capacity for rapid evolution. Genome Biol. 16, 71

Robinson, M.W. et al. (2009) An Integrated Transcriptomics and Proteomics Analysis of the Secretome of the Helminth Pathogen Fasciola hepatica: proteins associated with invasion and infection of the mammalian hos. Mol. Cell. Proteomics 8, 1891-1907

41 Driguez, P. et al. (2016) Clinical implications of recent findings in schistosome proteomics. Expert Rev. Proteomics 13, 19-33

Sotillo, J. et al. (2015) A quantitative proteomic analysis of the tegumental proteins from Schistosoma mansoni schistosomula reveals novel potential therapeutic targets. Int. J. Parasitol. 45, 505-516

Anuracpreeda, P. et al. (2008) Paramphistomum cervi: Antigenic profile of adults as recognized by infected cattle sera. Exp. Parasitol. 118, 203-207

Saifullah, M.K. et al. (2011) Isolation and partial characterization of excretory/secretory antigens of Gastrothylax crumenifer. Vet. Parasitol. 180, 232-236

45 Meshgi, B. et al. (2009) Determination of diagnostic antigens in cattle amphistomiasis using western blotting. Iran. J. Parasitol. 4, 32-37

46 Huson, K.M. et al. (2015) Identification of the Rumen fluke Calicophoron daubneyi infecting cattle in Wales. Adv. Anim. Biosci. 6, 183

Bellet, C. et al. (2016) Ostertagia spp., rumen fluke and liver fluke single- and polyinfections in cattle: An abattoir study of prevalence and production impacts in England and Wales. Prev. Vet. Med. 132, 98-106

Zintl, A. et al. (2014) Bovine paramphistomes in Ireland. Vet. Parasitol. DOI: 10.1016/j.vetpar.2014.05.024

Ploeger, H.W. et al. (2017) Presence and species identity of rumen flukes in cattle and sheep in the Netherlands. Vet. Parasitol. 243, 42-46

50 Malrait, K. et al. (2015) Novel insights into the pathogenic importance, diagnosis and treatment of the rumen fluke (Calicophoron daubneyi) in cattle. Vet. Parasitol. 207, 134-139

51 Rinaldi, L. et al. (2005) Characterization of the second internal transcribed spacer of 
ribosomal DNA of Calicophoron daubneyi from various hosts and locations in southern Italy. Vet. Parasitol. 131, 247-253

52 O'Toole, A. et al. (2014) Identity of rumen fluke in deer. Parasitol. Res. 113, 40974103

53 Jones, R.A. et al. (2017) The prevalence and development of digenean parasites within their intermediate snail host, Galba truncatula, in a geographic area where the presence of Calicophoron daubneyi has recently been confirmed. Vet. Parasitol. DOI: 10.1016/j.vetpar.2017.03.021

54 Iglesias-Piñeiro, J. et al. (2016) Transmission of Calicophoron daubneyi and Fasciola hepatica in Galicia (Spain): Temporal follow-up in the intermediate and definitive hosts. Parasit. Vectors 9, 610

55 Abrous, M. et al. (1999) Paramphistomum daubneyi and Fasciola hepatica: influence of temperature changes on the shedding of cercariae from dually infected Lymnaea truncatula. Parasitol. Res. 85, 765-769

56 Vignoles, P. et al. (2016) Calicophoron daubneyi and Fasciola hepatica: characteristics of natural and experimental co-infections of these digeneans in the snail Lymnaea glabra. J. Helminthol. DOI: 10.1017/S0022149X1500108X

57 Fuertes, M. et al. (2015) Immunohistochemical study and mRNA cytokine profile of the local immune response in cattle naturally infected with Calicophoron daubneyi. Vet. Parasitol. 214, 178-183

58 Coakley, G. et al. (2016) Host parasite communications-Messages from helminths for the immune system: Parasite communication and cell-cell interactions. Mol. Biochem. Parasitol. 208, 33-40

59 Cwiklinski, K. et al. (2016) A prospective view of animal and human Fasciolosis. Parasite Immunol. 38, 558-568

60 McSorley, H.J. and Maizels, R.M. (2012) Helminth infections and host immune regulation. Clin. Microbiol. Rev. 25, 585-608

61 Hewitson, J.P. et al. (2009) Helminth immunoregulation: The role of parasite secreted proteins in modulating host immunity. Mol. Biochem. Parasitol. 167, 1-11

62 Peterson, L.W. and Artis, D. (2014) Intestinal epithelial cells: regulators of barrier function and immune homeostasis. Nat Rev Immunol 14, 141-153

63 Anuracpreeda, P. et al. (2016) Antigenic profile, isolation and characterization of whole body extract of Paramphistomum gracile. Parasite Immunol. 38, 431-438

64 Anuracpreeda, P. et al. (2016) Production and characterization of a monoclonal antibody specific to $16 \mathrm{kDa}$ antigen of Paramphistomum gracile. Parasitol. Res. DOI: $10.1007 / \mathrm{s} 00436-016-5273-1$

Mezo, M. et al. (2004) An ultrasensitive capture ELISA for detection of Fasciola hepatica coproantigens in sheep and cattle using a new monoclonal antibody (MM3). J. Parasitol. 90, 845-852

66 Cwiklinski, K. et al. (2015) The Extracellular Vesicles of the Helminth Pathogen, Fasciola hepatica: Biogenesis Pathways and Cargo Molecules Involved in Parasite 
453

454

455

456

457

458

459

460

461

462

463

464

465

466

467

468

469

470

471

472

473

474

475

476

477

478

479

480

481

482

483

484

485

486

487

488

489

490

491

67 Tzelos, T. et al. (2016) A preliminary proteomic characterisation of extracellular vesicles released by the ovine parasitic nematode, Teladorsagia circumcincta. Vet. Parasitol. 221, 84-92

68 Marcilla, A. et al. (2012) Extracellular Vesicles from Parasitic Helminths Contain Specific Excretory/Secretory Proteins and Are Internalized in Intestinal Host Cells. PLoS One 7,

69 Nowacki, F.C. et al. (2015) Protein and small non-coding RNA-enriched extracellular vesicles are released by the pathogenic blood fluke Schistosoma mansoni. J. Extracell. Vesicles 4, 1-16

70 Robinson, M.W. et al. (2008) Helminth pathogen cathepsin proteases: it's a family affair. Trends Biochem. Sci. 33, 601-608

71 McGonigle, L. et al. (2008) The silencing of cysteine proteases in Fasciola hepatica newly excysted juveniles using RNA interference reduces gut penetration. Int. J. Parasitol. 38, 149-155

72 Toet, H. et al. (2014) Liver fluke vaccines in ruminants: strategies, progress and future opportunities. Int. J. Parasitol. 44, 915-927

73 Ahn, C.S. et al. (2015) An echinococcus multilocularis antigen b3 proteoform that shows specific antibody responses to active-stage alveolar echinococcosis. J. Clin. Microbiol. 53, 3310-3317

74 Jyoti et al. (2014) Evaluation of antibody response to various developmental stage specific somatic antigens of Paramphistomum epiclitum in goats. Biomed Res. Int. 2014 ,

75 Rose, H. et al. (2015) Widespread anthelmintic resistance in European farmed ruminants: a systematic review. Vet. Rec. 176, 546-546

76 Leathwick, D.M. and Besier, R.B. (2014) The management of anthelmintic resistance in grazing ruminants in Australasia-Strategies and experiences. Vet. Parasitol. 204, $44-54$

77 Panic, G. et al. (2013) Development of an in vitro drug sensitivity assay based on newly excysted larvae of Echinostoma caproni. Parasit. Vectors 6, 237

78 Chryssafidis, A.L. et al. (2015) Standardisation of egg-viability assays for Fasciola hepatica and Calicophoron daubneyi: A tool for evaluating new technologies of parasite control. Vet. Parasitol. 210, 25-31

79 Sanabria, R.E.F. and Romero, J.R. (2008) Review and update of paramphistomosis. Helminthologia 45, 64-68

80 Toolan, D.P. et al. (2015) Bovine and ovine rumen fluke in Ireland-Prevalence, risk factors and species identity based on passive veterinary surveillance and abattoir findings. Vet. Parasitol. 212, 168-174 


\section{Figure 1: Life-cycle of the rumen fluke, Calicophoron daubneyi}

494 Unembryonated eggs pass from the rumen, through the gastrointestinal tract and onto grazing 495 pasture in the host's faeces (1). Eggs embryonate under favourable environmental conditions 496 (adequate temperature and moisture) (2) and miracidia hatch from the egg and locate a 497 suitable snail intermediate host (typically Galba truncatula) (3). Within the snail host (4), 498 parasites reproduce asexually and develop through 3 larval stages (4a Sporocysts, 4b Rediae, $4994 \mathrm{c}$ Cercariae), before the free-swimming cercariae are released from the snail and encyst on 500 vegetation (5). Metacercariae remain dormant, resistant to moderate environmental changes, 501 until they are ingested by the definitive ruminant host (6). Parasites then excyst in the 502 duodenum of the small intestine (7) where immature flukes feed on sub-mucosa until they are 503 ready to begin their migration to the rumen. In the rumen, mature fluke attach firmly to the 504 rumen wall, or rumen papillae, via their muscular acetabulum, and release eggs into the 505 rumen contents (8).

506

\section{Figure 2: Images of rumen tissue recovered from a naturally infected cow at slaughter}

508 The area marked ' $A$ ' shows an example of the raised nodules seen where parasites attach to 509 the rumen wall. ' $B$ ' shows an area of papillae atrophy, commonly seen alongside rumen fluke 510 infection. $\mathrm{P}$, normal papilla. 


\begin{tabular}{lllll}
\hline Area & Host & Method $^{\text {a }}$ & Prevalence & Reference \\
\hline France & Goat & FEC & $58.1 \%$ & {$[34]$} \\
France & Cattle & PM & $20 \%$ & {$[23]$} \\
Belgium & Cattle & PM & $28 \%$ & {$[50]$} \\
& & FEC & $22 \%$ & \\
Ireland & Sheep & PM & $14 \%$ & {$[80]$} \\
& Cattle & PM & $52 \%$ & \\
Spain & Cattle & FEC & $36 \%$ & {$[22]$} \\
Spain & Cattle & PM & $6.2 \%$ & {$[17]$} \\
Wales & Sheep & FEC & $42 \%$ & {$[24]$} \\
& Cattle & FEC & $59 \%$ & {$[47]$} \\
Ireland & Cattle & FEC & $57-100 \%$ & {$[48]$} \\
Ireland & Sheep & FEC & $77 \%$ & {$[18]$} \\
& & & $25 \%$ & \\
\hline England & Cattle & PM & & \\
\hline
\end{tabular}

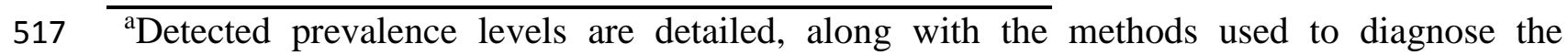
518 infections. FEC, faecal egg counts (farm level); PM, post mortem identification in the 519 slaughterhouse; ${ }^{\mathrm{b}}$, herd level. 
- Omics: Generally, the suffix '-omics' is used to describe large-scale studies which analyse the interactions of biological processes and specific molecule types within a particular cell, tissue type or organism, including (but not limited to) genes (genomics), transcripts (transcriptomics), proteins (proteomics) and small metabolites (metabolomics). Omics technologies encompass a range of tools and research platforms which enable a whole systems approach to studying molecular biology, and the analysis of omics data relies heavily on bioinformatics.

- Digenean: A subclass of organisms within the phylum Platyhelminthes and Class Trematoda, the digenea are obligate parasites with complex lifecycles, involving multiple hosts. Most commonly a molluscan first and vertebrate definitive host are required, with many species having $2^{\text {nd }}$ and $3^{\text {rd }}$ intermediate hosts also. Digenea are characterised by their syncytial tegument and usually two suckers - one oral, leading to the gut, and one muscular, which is blind-ended. Typically digenean parasites are hermaphroditic, with the Schistosomes a notable exception.

- Paramphistome: digenetic trematodes from the family Paramphistomidae that reside in the rumen of their definitive hosts, typically sheep and cattle. The term paramphistome refers to their two-mouthed appearance, with an anterior oral sucker and posterior muscular sucker which is used for attachment to the host.

- Rumen: The rumen is the second of the four stomach chambers described in ruminant mammals, although the term is commonly used to refer to the single organ formed by both the reticulum (first chamber) and rumen. The primary role of this chamber is the microbial degradation of ingested plant materials and for the uptake of volatile fatty acids produced by microbial fermentation. 
547 - Helminth parasites impact hugely on livestock productivity by affecting growth rates, 548 fertility, meat quality, wool or milk production, and sometimes cause mortality.

- Levels of infection with the rumen fluke, Calicophoron daubneyi, have increased dramatically in the UK and Ireland in recent years and may exceed that of liver fluke (Fasciola hepatica) in some areas.

552 - There are a growing number of reports of animal morbidity and mortality associated with acute paramphistomosis.

554

- Current diagnostic and treatment options are very limited, and improving these will depend on answering basic questions about rumen fluke biology.

556

557 
- What is the impact of chronic $C$. daubneyi infection on animal health, welfare and production?

- How do immature $C$. daubneyi contribute to the pathology of infected animals?

- What is the mechanism of feeding used by immature and mature $C$. daubneyi in the small intestine and rumen respectively?

- Adult C. daubneyi are often said to be "well tolerated" by their hosts. What does this mean for the host and what (if any) parasite-derived molecules drive it?

- Can we identify new drugs or drug targets to help control rumen fluke infection?

- Since pre-patent infections are the primary cause of clinical paramphistomosis, can we identify antigens specific to early stage rumen fluke infection, to enable timely diagnosis and treatment?

- What immune response does the host mount against rumen fluke and is this amenable to vaccine design?

- What is the outcome of potential competition between $C$. daubneyi and $F$. hepatica within an intermediate snail host population? What impact does this have on 


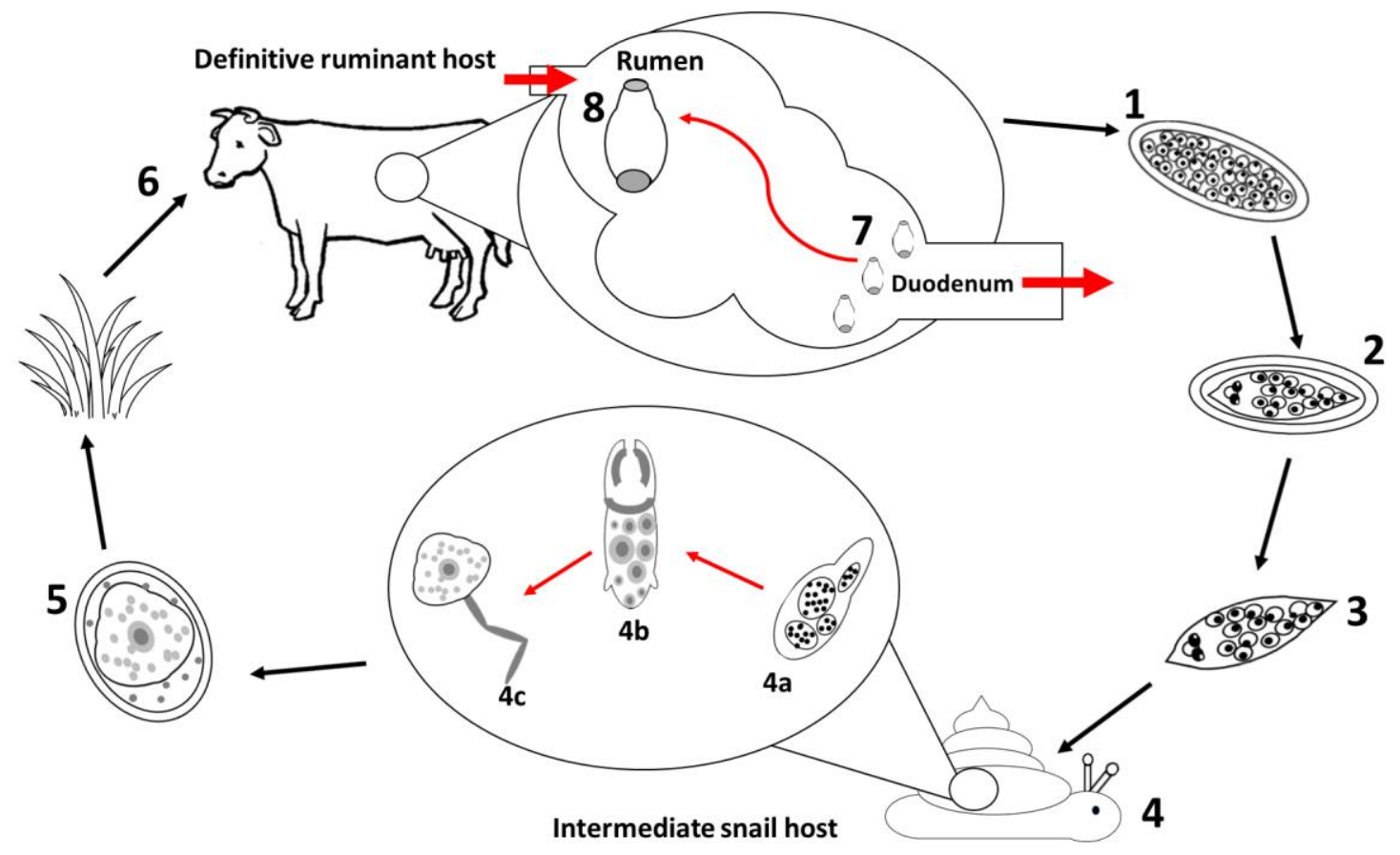


$581 \quad$ Figure 2

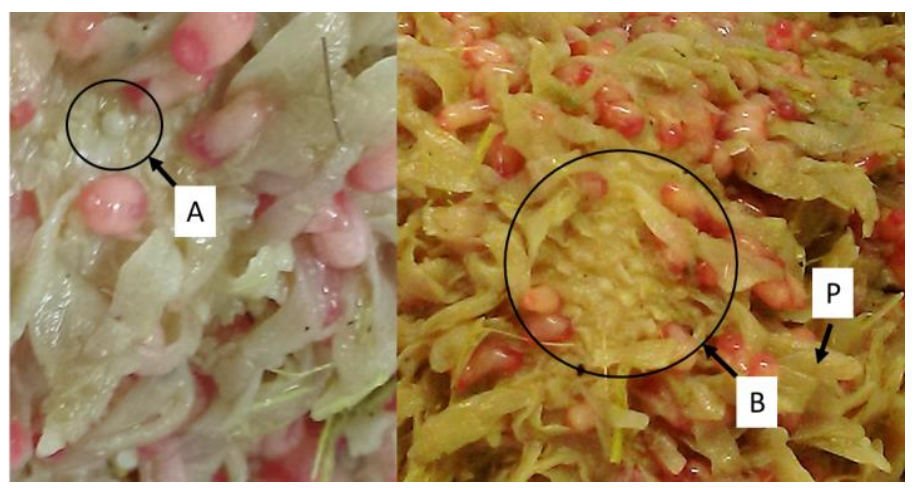

582 